PART 2

Students \& Faculty 


\title{
International Faculty Mobility
}

Crucial and Understudied

\author{
Laura E. Rumbley and Hans de Wit
}

The presence of international (i.e., foreign, nonlocal, or nondomestic) faculty within higher education institutions and systems around the world is an important dimension of higher education in the global knowledge society of today. Increased global competition for talent, research, funding, and reputation/profile/branding not only implies that universities must compete for the best and brightest of undergraduate and graduate students, but they must also seek out talented researchers and teachers on a worldwide scale.

The international mobility of faculty is also important in relation to the specific phenomenon of internationalization of higher education. Here, we note that such elements as student mobility, curricular innovations, and the cultivation and maintenance of international partnerships are fundamental aspects of many institutional strategies for internationalization - and in all three areas, faculty are crucial actors.

Yet, the scope and nature of international mobility of faculty — particularly in relation to permanent or long-term appointments, rather than short-term or occasional visits-is a rather unknown and understudied phenomenon. Compared to the long list of reports and studies on international student mobility, there is a surprising lack of data and studies on the phenomenon of international faculty mobility. As we seek to gain an ever-clearer understanding of the dynamics implicit in the global circulation of academic talent (at all levels), it is vital to gain insight into what motivates academics to pursue permanent or long-term appointments abroad, why institutions and systems of higher education hire these individuals, how the relationships between mobile academics and their host institutions play out in practical terms, and what effects are exerted by national and institutional policies relevant to long-term faculty mobility. Indeed, recent research on this subject in which we have been involved-encompassing perspectives from eleven different countries and specific universities-suggests that international faculty mobility is a growing and complex phenomenon, fraught with possibilities and inequalities, and ripe for extensive further exploration and analysis.

(C) INTERNATIONAL HIGHER EDUCATION, 2017 | DOI: 10.1163/9789004418912_006

This is an open access chapter distributed under the terms of the CC-BY 4.0 License.

Laura E. Rumbley and Hans de Wit - 9789004418912 
Just as there are a number of different ways in which internationally mobile students are defined or categorized around the world, there is also a lack of consensus with respect to what defines an "international" academic. Is citizenship the defining factor? Or does status as internation.al faculty member have more to do with having received one's academic training (for example, completing doctoral studies) abroad, regardless of country of origin? Is an international faculty member someone who is considered an "immigrant" in the local context-and, if so, does it matter if this process of immigration occurred before or after the faculty member entered the ranks of academia? Without definitional clarity or consistency, it is exceedingly difficult to compare and contrast both quantitative and qualitative information related to this population.

Meanwhile, there are also very different profiles for the institutions recruiting these individuals. On one end of the spectrum, we may find elite research universities with "superstar" attraction status. These institutions are in a position to recruit the world's most sought-after academics and, indeed, consider all faculty searches to be essentially global in nature, as they seek out the best talent from anywhere in the world. Among the scant literature on international faculty mobility, a considerable amount of attention has been paid to these kinds of prestigious institutions. At the other end of the spectrum, however, there are institutions or systems facing local shortages of faculty, which recruit regional or international faculty in order to meet basic operational needs. In between these two extremes, a range of middle-and upper-tier universities may actively be seeking out international academics to some degree, or simply responding as needed to nonlocal job seekers.

How we define international faculty around the world remains inconsistent, and the landscape of institutional settings in which foreign faculty are employed is tremendously diverse.

It is impossible to make generalizations about internation.al faculty mobility without extensive and in-depth analysis over time. However, our research suggests that making sense of the international faculty mobility experience anywhere in the world hinges on an understanding of the distinct, yet interlocking, dynamics of policy and practice at the national and institutional levels, while 
taking into account the complex realities of the fundamental human experience at the level of individual academics themselves.

At the national level, potential foreign faculty are presented with a set of tangible and intangible factors and options. Whether they will find them attractive or not depends on a multitude of variables. These variables range from the policy framework that actively stimulates (or complicates) their recruitment and legal or professional status in the country, to the aspects of daily lifesuch as language, cultural norms, and practices - that enable (or inhibit) their integration, to the broader issues of geopolitics and the environment, which can set the overall tone and tenor for their own experience and that of any family members who may accompany them. The national context is therefore a crucial dimension of the international faculty story.

Meanwhile, the lives of internationally mobile faculty are also colored heavily by the circumstances they face with.in the specific institutional context where they are hired.

Our research indicates that there is a range of rationales for international faculty recruitment and a wide array of ways in which foreign academics are recruited. Terms of employment can also differ-they may be identical to those offered to domestic faculty, or unique for internationals, with either scenario potentially resulting in challenges and opportunities for all involved. Further, the manner and extent to which the presence of foreign faculty exerts an impact on their host institutions seems rarely explored, documented, or leveraged systematically.

Finally, the story of international faculty mobility is not complete without a consideration of what this phenomenon means at the most fundamental level — that of the individual academic. Here, our research shows that mobile faculty are often motivated by attractive employment opportunities or a sense of duty or desire to contribute to a "larger agenda" that they believe in. They are sensitive to the personal supports that the host institution or country can provide. The universities examined in our study, however, vary widely in terms of systematic provision of such supports.

There is much to explore and yet to understand about the international faculty mobility phenomenon. Some of the key issues we see on the horizon for future research include the way immigration/migration policies affect international faculty mobility; international faculty mobility in developed versus emerging 
societies, in the public higher education sector versus the private and for-profit sectors, and across disciplines, age, and gender; the impact of online education on international faculty mobility; and the differences in the realities of faculty mobility across various institutional types.

\section{Acknowledgement}

This chapter was previously published in International Higher Education, No. 88, Winter 2017 (pp. 6-8). Reprinted here with permission. 